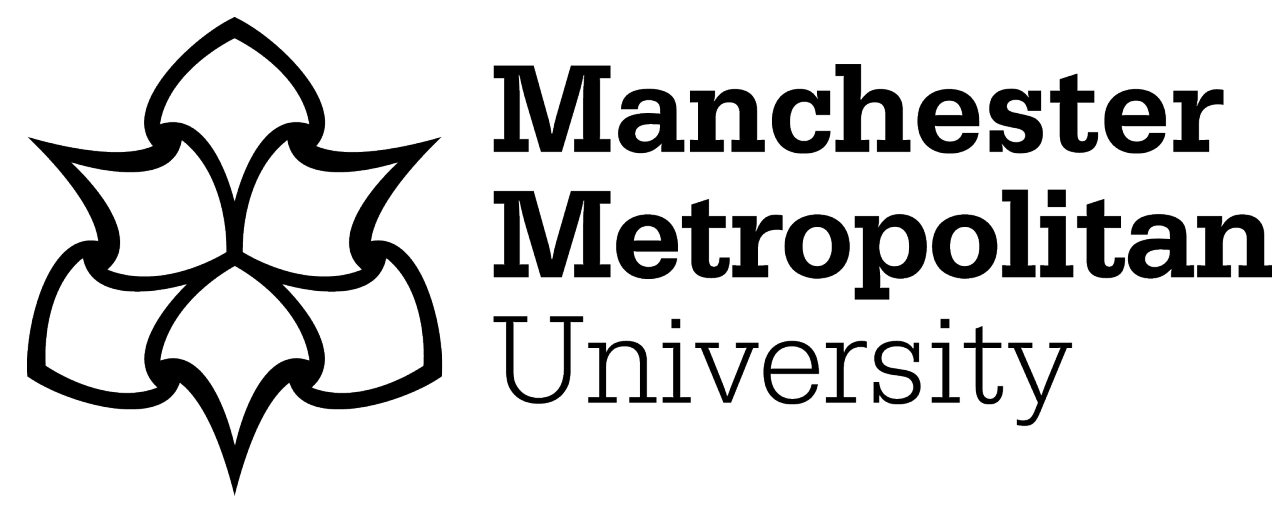

Moretti, A ORCID logoORCID: https://orcid.org/0000-0001-6543-9418 and Whitworth, A (2020) European Regional Welfare Attitudes: a Sub-National Multi-Dimensional Analysis. Applied Spatial Analysis and Policy, 13 (2). pp. 393-410. ISSN 1874-463X

Downloaded from: https://e-space.mmu.ac.uk/625177/

Version: Accepted Version

Publisher: Springer (part of Springer Nature)

DOI: https://doi.org/10.1007/s12061-019-09309-3

Please cite the published version 


\title{
European regional welfare attitudes: a sub-national multi-dimensional analysis
}

\author{
Angelo Moretti ${ }^{1}$ and Adam Whitworth ${ }^{2}$ \\ ${ }^{1}$ Social Statistics Department, University of Manchester, UK \\ ${ }^{2}$ Department of Geography, University of Sheffield, UK \\ ${ }^{1}$ Correspondent author: angelo.moretti@manchester.ac.uk and a.moretti2@outlook.com
}

ORCID: 0000-0001-6543-9418

${ }^{2}$ ORCID: 0000-0001-6119-9373

\begin{abstract}
Public attitudes to welfare are key issues in social policy research and practice given their important roles in shaping demands for different types of welfare policies as well as the political parameters within which those welfare decisions are made by governments. Research into headline trends has shown important hardenings in public attitudes to welfare cross-nationally. However, more detailed geographical analysis of these patterns of welfare attitudes sub-nationally remains an important and surprisingly neglected area of understanding, in part due to the lack of suitable survey datasets with which to create sufficiently reliable direct sub-national comparative estimates. Responding to these gaps, this article employs small area estimation techniques to present reliable sub-national estimates and analyses of distinct economic, moral and social welfare attitudes across European regions for the first time in the literature. Compared to previous national analyses the richer spatial understanding enabled in these original analyses reveals previously neglected variation in welfare attitudes within as well as across national boundaries. Five geodemographic 'families' of regional welfare attitudes are found across Europe's regions - from strong welfare supporters to consistent welfare sceptics - with their regional memberships cutting across national boundaries and current welfare typologies.
\end{abstract}

Keywords: welfare attitudes; welfare legitimacy; welfare consequences; welfare typology; small area estimation; composite estimation; European Social Survey

\section{Public attitudes of welfare benefits and their consequences}

Debates around public attitudes for and against welfare benefits are an important and lively topic of social policy research in the post-crash context of polarising politics and on-going fiscal restraint (Svallfors and Taylor-Gooby, 2012; Svallfors, 2012; Taylor-Gooby and Leruth, 2018). Understanding the trends in those welfare attitudes, as well as the drivers of those trends, is imperative given the important feedback loops between public welfare attitudes and the political context within policy decisions around the generosity or hardening of welfare systems are debated, made and legitimized (Jakobsen, 2011; Taylor-Gooby, 2011; Breznau, 2017). Moreover, the on-going trends across many European nations away from mainstream political parties and positions and instead towards more polarised extremes makes the present moment a particularly salient one in which to explore welfare attitudes. The rise of myriad international social movements in recent years including gilets jaunes, \#MeToo, Occupy and Extinction Rebellion testify to a widespread dissatisfaction with the 
current status quo and a clamour for change. This is reflected in the growing polarisation of formal politics in many countries away from mainstream centre-ground positions and parties and instead towards more extreme and polarised attitudes that have created surges in support for parties at the more extreme ends of the political left (e.g. Syriza in Greece, Left Bloc in Portugal) and right (e.g. National Front in France, Lega Nord in Italy, UKIP in the UK) as well as by the emergence of entirely new parties (e.g. En Marche in France, Podemos in Spain, Brexit Party in the UK). Nowhere perhaps in this attitudinal polarisation more apparent than in the UK context where Brexit has emerged as a radical rejection of the status quo and rupture of traditional party alliances and where increasingly polarised views around remain or hard Brexit continue both to swamp and paralyse British politics.

Within this wider political context in which welfare attitudes rest one strand of research in the field has advanced understanding of the different ways in which a range of factors across individuals, households, communities and national contexts affect welfare attitudes (Blekesaune and Quadagno, 2003; Svallfors; 2004; Roosma et al., 2014; Toikko and Rantanen, 2017; Laenen, 2017). This scholarship has highlighted important ways in which an individual's structural socio-economic position tends to relate to their attitudes to welfare, though with a layering of ideological views mediating that relationship for some. Individuals struggling to make ends meet, for example, are associated with a critical appraisal of the performance of welfare systems. Individuals with comfortable financial positions, however, are interestingly split between those broadly supportive of welfare systems irrespective of their political leanings and those individuals with right-leaning political views who are fundamentally critical of the role and egalitarian aims of welfare systems. Individual's selfinterested assessments of how much they and their family have to gain from particular aspects of welfare system unsurprisingly matter to welfare attitudes, but so too do perceptions of system performance, fairness, deservingness and financial cost and sustainability.

A second research strand has provided valuable insights into the apparent mismatch between attitudes and empirical reality around welfare systems. In recent European cross-national analyses Baumberg (2017) also provides important new insights to this potential mismatch between welfare attitudes and welfare realities. In cross-national survey analyses they find that, despite some areas of empirical accuracy in attitudes, the public generally show low levels of understanding and accuracy of the welfare benefits systems and in ways that are systematically prone to underestimate their support for those welfare systems. Such analyses of attitudinal-empirical mismatch are important and much needed. Part of what is underpinning this shift is believed to be the public's beliefs in various 'myths' around both the levels of social benefit payments and social benefit recipient themselves (Beresford, 2013). Indeed, a strand of research has emerged focusing on highlighting the 'welfare myths' that have been deliberated cultivated and circulated by central governments of all colours over the period in concerted efforts to 'story' welfare and shape welfare attitudes (Wiggan, 2012; Slater, 2012).

A third strand of research from which the present article extends has been the surprising lack of empirical understanding around the issue of what people think are the consequences of social welfare benefits (van Oorschott, 2010). Recent empirical work has responded to this gap at national level, highlighting in a series of innovative cross-national pieces the multidimensional latent nature of these welfare attitudes and advancing empirical understanding of national positions across these latent dimensions (van Oorschott, 2010; van Oorschott et al., 2012; Roosma et al, 2013). Framed around the public's attitudes towards both the range and extent of activities that welfare systems ought legitimately to seek to do (Roller, 1995), these 
analyses helpfully separate out attitudinal dimensions relating to distinct economic, social and moral consequences of welfare benefits and examine the factors associated with holding these distinct welfare attitudes.

Although these new research insights provide valuable contributions to our understanding of welfare attitudes current scholarship and understanding remain importantly limited in their continued neglect of the spatial patterning of public attitudes to welfare below the headline level of the nation state. National level rankings and typologies of welfare attitudes of the sort developed in Roosma et al. (2013) remain valuable at a summary level, but the continued neglect of sub-national welfare attitudes is surprising given that the vast majority of any country's variation in social, economic or attitudinal indicators such as this typically occur within rather than between nation states and are therefore significantly smoothed or averaged as one aggregates the level of analysis up to the national level. The national level undoubtedly remains key for analysis and policymaking. Nevertheless, local governments have become key points in the formulation and implementation of welfare policies in most western countries. These relate to a large variety of services such as nurseries, primary and secondary education, transport, police, health services and adult social care. Policy makers and citizens alike are interested in understanding the effects of social policies in and across the areas where they live rather than at relatively abstracted national scales (Hansen and Klausen, 2010; Pratesi, 2016). For these reasons, filling the void of sub-national understanding in welfare attitudes remains an important analytical and policy need.

Responding to this continuing gap in sub-national understanding of welfare attitudes and their consequences is the focus of the present article. One important limiting factor to the previous advancement of understanding in this area is the lack of suitable large-scale survey data with which to create reliable sub-national estimates of welfare estimates. In response, the analyses below make use of composite small area estimation techniques combining direct and synthetic estimators in order to provide original sub-national estimates of welfare attitudes in a comparative perspective across European regions based on the cross-national European Social Survey (ESS). In doing so these new cross-national European data on welfare estimates add valuable new insights for scholars and policy makers alike about the subnational spatial patterns of these key social, political and policy factors.

The next section sets out the data and methods used and this is followed by analysis of those estimates in Section 3. Section 4 progresses to question the dominance both of the nation state as the appropriate spatial unit of analysis within welfare attitudes scholarship as well as common groupings within existing welfare typologies through the use of geodemographic analysis to derive five families of regional European welfare attitudes that cut across national boundaries. A final discussion section concludes with consideration of wider implications and future research priorities in the field.

\section{Data and Methods}

The cross-national analyses presented in this paper draw on the most recent European Social Survey (ESS) 2016 (round 8) dataset. ESS is a nationally representative European crossnational survey that has been running bi-annually since 2001. National sample sizes are relatively modest give that the primary survey purpose is to enable comparative analyses across Europe at the national level. Descriptive statistics of the sample size across regions are the following $\operatorname{Min}=14,1$ st Quartile $=90$, Median $=153$, 3rd Quartile $=264$, Max $=$ 2019. Descriptive statistics of the sampling fractions are given by $M i n=$ $0.000018,1$ st Quartile $=0.000036$, Median $=0.000088,3$ rd Quartile $=$ 
$0.00021, \operatorname{Max}=0.0015$. As such, reliable direct sub-national comparative analysis is not possible by using the ESS survey sample only for many of the regions. Furthermore, in the vast majority of the ESS countries statistical inference cannot be performed for those subnational levels (see European Social Survey, 2018).

The 2016 round of the ESS includes data from 23 countries of which 15 were able to be included in these analyses: Austria, Belgium, Switzerland, Czech Republic, Germany, Estonia, Finland, France, United Kingdom, Ireland, Netherlands, Norway, Poland, Sweden and Slovenia. The final sample size across the 15 nations used in the analyses is 26,521 individuals. Countries that did not have regional information in the data, that did not match the NUTS classification and that did not offer comparable auxiliary data from administrative and/or Census sources were by necessity excluded from the analyses. In particular, Israel and Russian Federation were excluded since the do not adopt the NUTS European classification. Remaining countries were excluded because of the lack of all reliable auxiliary information that lead on good statistical models. Regional estimates are estimated to the NUTS-2 level in all nations except for UK and Germany where due to data constraints estimates are produced at NUTS-1 level. NUTS-2 is a regional level classification of European areas with a mean of 1.9 million residents and wide range from a minimum of 29,500 residents (Åland) to a maximum population size of 12.2 million residents (Ile de France) amongst the areas included in these analyses (Eurostat, 2019).

In order to analyse welfare state attitudes cross-nationally across Europe we focus on six ESS items identified by van Oorschot et al. (2012) and also available in the latest ESS round 8 data. These questions are phased as follows in the survey: 'To what extent do you disagree or agree that social benefits and services in [country]:

1. place too great strain on the economy?

2. cost business too much in taxes and charges?

3. prevent widespread poverty?

4. lead to a more equal society?

5. make people lazy?

6. make people less willing to care for one another?'

Responses to these six questions are coded according to a Likert scale 1 (Agree) to 5 (Disagree strongly). Rather than conduct the analyses on these six indicators separately a first methodological step uses confirmatory factor analysis (CFA) to create three distinct economic, moral and social latent dimensions. The rationale for doing so rather than analysing the six indicators separately is three-fold: this approach and the three latent dimensions are already established in the literature (van Oorschott et al., 2012); they offer a more meaningful conceptual basis for analysis compared with a simple indicator list without any conceptual organisations; and the resulting economic, moral and social latent dimensions show good results in terms of model diagnostics. These latent factor scores can be defined as composite variables providing information on an individual's placement on the latent factor. Technically, they are estimated via a confirmatory factor analysis (CFA) model using the Bartlett estimator which produces unbiased factor scores (Hershberger, 2005; DiStefano et al, 2009). Bartlett factor scores are obtained by multiplying the vector of observed variables by the inverse of the diagonal matrix of variances of the unique factor scores, and the factor pattern matrix of loadings (DiStefano et al, 2009). 
Small area estimation is a family of methodological approaches increasingly in demand from researchers and policy makers alike due to the growing demand for richer spatial understanding and the financially prohibitive cost of collecting sufficiently large survey samples to enable reliable direct estimation of many key variables of interest to smaller geographies. Small area estimation can be performed in a variety of ways (for reviews see Ghosh and Rao, 1994; Rahman 2008; Marshall 2011; Whitworth, 2013; Rao and Molina, 2015) but is at heart always based on two key steps: firstly, the quantification of relationships found between explanatory characteristics and target outcome variables in a (typically national) survey dataset; and, secondly, the application of those relationships to the same set of (often Census) explanatory characteristics at the target small area level. The result is a new estimate for the target parameter(s) of interest at the small area level offering valuable new spatially information for policy makers and analysts.

The small area estimation approach adopted here makes use of an Empirical Best Linear Unbiased Predictor (EBLUP) composite estimator that combines direct estimates based on the Horvitz-Thompson survey estimator with synthetic estimates based on the Fay-Herriot model (Fay and Herriot, 1979). Each of these commonly used estimators is explained in greater detail below. These direct and synthetic estimators are combined within the composite estimator according to a shifting weighting factor dependent upon the variance of the direct estimator. Specifically, more weight is attached to the direct estimate when the variability of the direct estimate is small and, conversely, more weight is given to the synthetic estimate when the variability of the direct estimate is large (Rao and Molina, 2015). The rationale for utilising such a composite estimator is to optimise the resulting estimates in terms of the minimisation of their bias and variance when compared with either the direct or synthetic estimators separately (see also Moretti and Whitworth, 2019). This is because whilst direct estimates are unbiased they, firstly, display high variance at low sample sizes and, secondly, cannot be used with zero sample sizes for small areas in the survey - both common features of nationally representative surveys in the small area estimation context. Synthetic estimators can improve performance in such scenarios with the relative attractiveness of the direct estimator increasing as the target small area sample size in the survey increases (and hence the variance of the direct estimator decreases).

Within this composite estimator the direct estimates are derived from the Horvitz-Thompson direct estimator using the design weights given by the sample surveys as is standard for direct survey estimation. Thus, as outlined below when the survey sample size for a small area is small the estimator returns large variance, and vice versa (Horvitz and Thompson, 1952; Rao and Molina, 2015). The synthetic estimates are derived from the Fay-Herriot model which is a widely used area-level model in the small area context. Area-level small area models are particularly helpful when, as here, Census or administrative covariates are not available for the individual micro-level units of the population. Instead, area-level models require aggregated covariates of the population from the Census or other external (e.g. administrative, commercial) reliable data sources (see Rao and Molina, 2015).

Whilst Section 3 focuses on discussion of the small area estimates themselves, Section 4 uses cluster analysis to explore regional 'families' of welfare attitudes sub-nationally across Europe. In order to identify these families a k-means cluster analysis is performed in order to bring together regions with similar attitudinal levels into shared groups and to push apart regions with dissimilar attitudinal levels into different welfare attitude families (see Bartholomew et al., 2008). 


\section{European regional welfare attitudes}

Table 1 shows the resulting factor loadings estimated from the CFA and the percentage (\%) of 'strongly agree' and 'agree' ESS survey responses on the 6 variables available. The CFA goodness of fit statistics show good model fit (RMSEA $=0.024, \mathrm{CFI}=0.997$ and TLI $=0.992$ ) (Hu and Bentler, 1999). The factor loadings give the following interpretation: higher values on the economic and moral dimensions convey more positive attitudes towards welfare spending whilst higher values on the social dimension convey more negative attitudes towards welfare spending.

\begin{tabular}{|c|c|c|c|c|}
\hline \multirow{2}{*}{$\begin{array}{l}\text { To what extent do you disagree } \\
\text { or agree that social benefits and } \\
\text { services in [country]... }\end{array}$} & \multirow{2}{*}{$\begin{array}{l}\text { Strongly agree } \\
\text { and agree }(\%)\end{array}$} & \multicolumn{3}{|c|}{ Factor loadings } \\
\hline & & Economic & Social & Moral \\
\hline $\begin{array}{l}\text { place too great strain on the } \\
\text { economy? }\end{array}$ & 37.65 & 1.00 & & \\
\hline $\begin{array}{l}\text { cost business too much in taxes } \\
\text { and charges? }\end{array}$ & 35.21 & 0.89 & & \\
\hline prevent widespread poverty? & 63.82 & & 1.00 & \\
\hline lead to a more equal society? & 53.14 & & 0.94 & \\
\hline make people lazy? & 45.06 & & & 1.00 \\
\hline $\begin{array}{l}\text { make people less willing to care } \\
\text { for one another? }\end{array}$ & 39.98 & & & 0.77 \\
\hline
\end{tabular}

Whilst van Oorschott's emphasis is the exploration of country-level factors to the national scores on these three latent dimensions of welfare attitudes (van Oorschott et al., 2012) our focus is instead to push sub-national spatial understanding of comparative welfare attitudes across Europe. Given that the limited ESS survey sample sizes preclude the production of reliable direct estimates at sub-national levels the present analyses utilise small area estimation techniques to produce these regional cross-national estimates of welfare attitudes for the first time in the literature.

Table 2 shows the results of the Fay-Herriot regression modelling for the three economic, social and moral dimensions of welfare attitudes across the 137 regions of the 15 European countries analysed. As outlined above, these estimates do not represent the final small area estimates derived from the composite estimator but instead form the synthetic part of that composite estimator. Relevant characteristics relating to economic wellbeing, education, crime and key demographic characteristics are incorporated into the model as set out in Table 2. These cross-nationally comparable explanatory data are sourced for each region from the Eurostat Census Hub portal ${ }^{2}$ and Eurostat regions database ${ }^{3}$. The R-squared value highlights that these explanatory factors are effective at explaining the variance in these welfare attitudes with between around one half (economic welfare attitudes) and three-quarters (social welfare attitudes) of the total variance in these variables explained by the models.

\footnotetext{
${ }^{1}$ Agree strongly (1) and Disagree strongly (5) in the scale from 1 to 5. Refusal and Don't Know categories are excluded.

${ }^{2}$ http://ec.europa.eu/eurostat/web/population-and-housing-census/census-data/2011-census

$3 \underline{\mathrm{http}: / / \text { ec.europa.eu/eurostat/web/regions/data/database }}$
} 


\begin{tabular}{|c|c|c|c|c|c|c|}
\hline & \multicolumn{2}{|c|}{ Economic } & \multicolumn{2}{|c|}{ Social } & \multicolumn{2}{|c|}{ Moral } \\
\hline & $\mathbf{B}$ & S.E. & $\mathbf{B}$ & S.E. & $\mathbf{B}$ & S.E. \\
\hline Constant & 10.571 & 4.865 & 1.712 & 2.883 & 13.787 & 5.462 \\
\hline \multicolumn{7}{|l|}{ Economic wellbeing } \\
\hline Low work intensity & -0.007 & 0.006 & -0.010 & 0.003 & 0.000 & 0.006 \\
\hline Severe material deprivation & -0.008 & 0.012 & 0.014 & 0.007 & -0.020 & 0.013 \\
\hline At-risk-at-poverty rate & 0.005 & 0.004 & -0.003 & 0.002 & 0.002 & 0.004 \\
\hline Long-term unemployment & -0.001 & 0.002 & 0.002 & 0.001 & -0.002 & 0.002 \\
\hline \multicolumn{7}{|l|}{ Education } \\
\hline Participation rates in levels 1,2 & -0.002 & 0.015 & 0.014 & 0.009 & 0.006 & 0.016 \\
\hline Participation rates in levels 5 to 8 & -0.001 & 0.000 & 0.001 & 0.000 & -0.001 & 0.000 \\
\hline \multicolumn{7}{|l|}{ Crime } \\
\hline Robbery & 0.031 & 0.029 & -0.011 & 0.017 & 0.044 & 0.032 \\
\hline Burglary & -0.001 & 0.010 & -0.006 & 0.006 & -0.003 & 0.011 \\
\hline Theft of vehicle & -0.016 & 0.019 & -0.001 & 0.011 & -0.025 & 0.021 \\
\hline \multicolumn{7}{|l|}{ Demographic characteristics } \\
\hline Gender & -3.927 & 2.960 & -1.609 & 1.754 & -6.503 & 3.323 \\
\hline Age & 0.069 & 0.015 & 0.020 & 0.009 & 0.062 & 0.017 \\
\hline Never married & -6.151 & 4.409 & 2.205 & 2.613 & -10.844 & 4.951 \\
\hline Married & -6.704 & 4.484 & 2.646 & 2.657 & -11.746 & 5.035 \\
\hline Widowed & -19.199 & 5.983 & -1.577 & 3.545 & -20.983 & 6.717 \\
\hline Divorced & -7.702 & 4.803 & 2.652 & 2.846 & -10.746 & 5.393 \\
\hline Life expectancy & -0.049 & 0.017 & -0.050 & 0.010 & -0.014 & 0.019 \\
\hline $\mathbf{R}^{2}$ & \multicolumn{2}{|c|}{0.496} & \multicolumn{2}{|c|}{0.739} & \multicolumn{2}{|c|}{0.638} \\
\hline $\mathbf{n}$ & \multicolumn{2}{|c|}{137} & \multicolumn{2}{|c|}{137} & \multicolumn{2}{|c|}{137} \\
\hline
\end{tabular}

Table 2 Area-level covariates used to produce EBLUP estimates under Fay-Herriot model.

These Fay-Herriot modelling results highlight that the synthetic estimates offer a solid component to the composite small area estimator alongside the direct estimates. Validation is an essential part of any small area estimation process however. For model diagnostics in small area estimation we refer to Brown et al (2001) and Scarborough et al (2009). Therefore, further diagnostic checks via Q-Q plots of standardized residuals and bias diagnostic plots of the direct estimates versus the model-based synthetic estimates were carried out and these 
also validate positively ${ }^{4}$. Finally, although the direct estimates suffer from higher variance at lower sample sizes they remain design-unbiased. Therefore, if one has relatively unbiased (but, crucially, with lower variance) model-based synthetic estimates then one would see a particular linear relationship between those two sets of direct and synthetic estimates. Specifically, if the two sets of estimates were set up as a simple bivariate linear regression and they were perfectly identical then the value of $\mathrm{R}^{2}$ (model power) would be 1 , the intercept estimate would be 0 (i.e. the two sets of estimates share an origin of 0 ) and the slope coefficient would be 1 (i.e. the two sets of estimates lie on a perfect $45^{\circ}$ line to each other). Table 3 presents these validation diagnostics (with confidence intervals around point estimates shown in brackets) for our synthetic small area estimates. Taken together Table 3 highlights excellent fit against the direct survey estimates across all three metrics. This suggests that the synthetic estimates are acceptable to use as part of our composite estimator.

\begin{tabular}{lccc}
\hline $\begin{array}{l}\text { Welfare attitudes } \\
\text { dimension }\end{array}$ & $\begin{array}{c}\text { Model } \\
\text { Power }\end{array}$ & Intercept & Slope \\
\hline Economic & 0.96 & $0.00(-0.002,0.007)$ & $1.12(1.091,1.190)$ \\
Social & 0.94 & $0.00(-0.004,0.005)$ & $1.08(1.091,1.152)$ \\
Moral & 0.93 & $0.00(-0.004,0.001)$ & $1.12(1.091,1.180)$ \\
\hline
\end{tabular}

Table 3 Performance of the synthetic estimates against the direct survey estimates, entries in parenthesis are lower and upper bounds of confidence intervals.

Figure 1 shows the performance comparison of the direct survey estimates and our resulting overall composite small area estimates. Performance is shown across the full distribution of regions sorted from left to right on Figure 1 according to increasing sample size in the ESS survey data or, equivalently, in terms of decreasing variance of the direct survey estimates. For each of the three dimensions of welfare attitudes performance is measured as the percentage reduction in the mean squared error of the composite estimates (which combines bias and variance) as compared to the variance of the direct estimates (given that the direct estimates are unbiased) (Rao and Molina, 2015; González-Manteiga et al., 2008; Moretti, Shlomo and Sakshaug, 2019; Buil-Gil, Medina and Shlomo, 2019). Figure 1 shows that across all regions more reliable estimates can be produced using our composite estimator than via the direct estimator alone. The gains in performance are markedly larger when the regional survey sample size is smaller, reflecting the large variance around the direct estimates for these areas. As the regional survey sample size increases the composite estimator gradually attaches increasing weighting to the direct rather than synthetic component as the variance around the direct estimates decreases such that the composite estimator tends to converge to the direct estimator towards the right of Figure 1.

\footnotetext{
${ }^{4}$ Full details from the diagnostic checks are available upon request from the authors.
} 


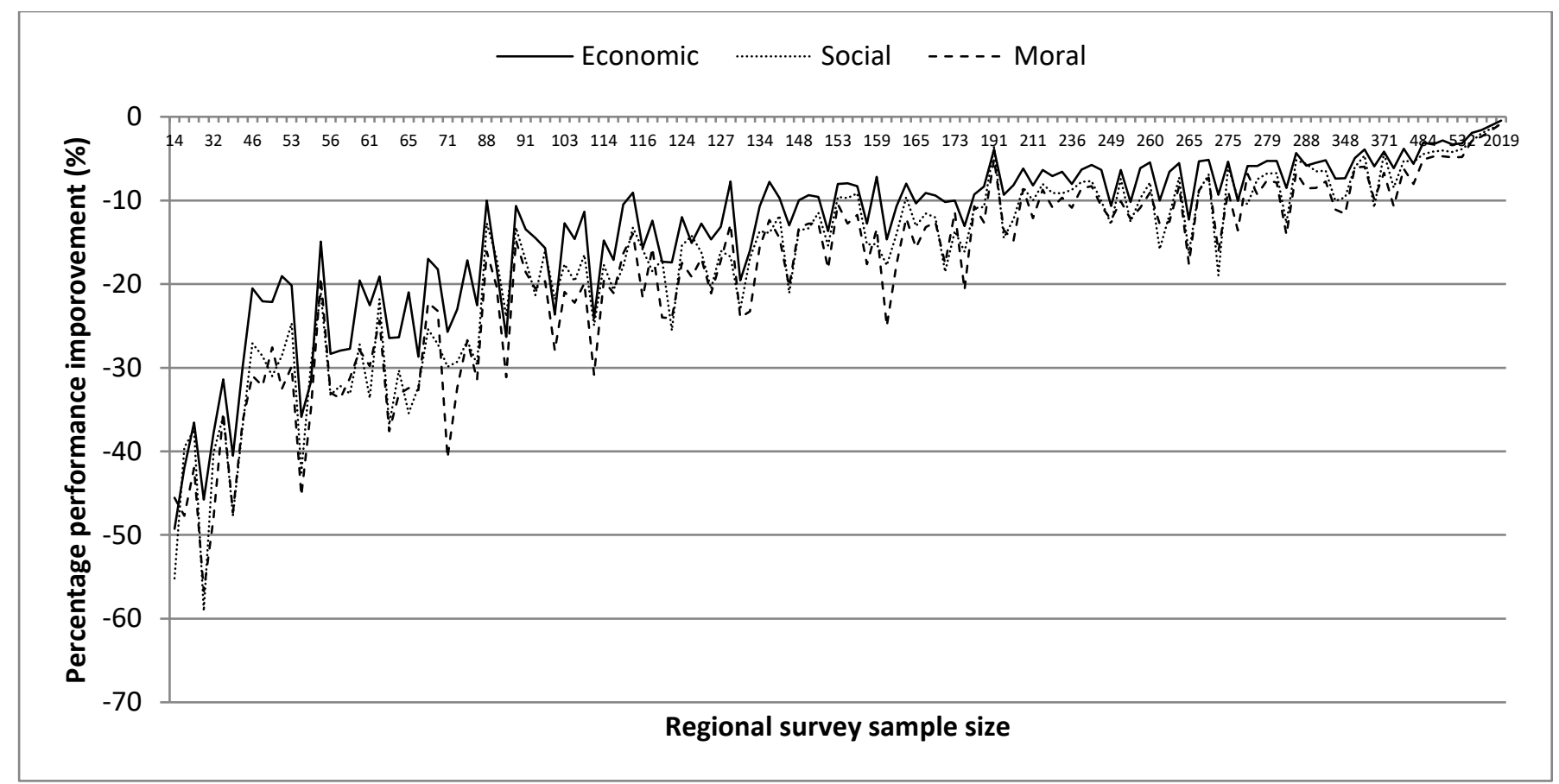

Figure 1 Performance gains of the composite estimator compared to the direct estimator across regions of differing survey sample size

Figures 2-4 show the composite estimates of regional welfare attitudes for all 137 regions of these 15 European nations across their three economic, moral and social latent dimensions. The scores are rescaled for ease of interpretation between zero and one using min-max range standardisation (OECD-JRC, 2008; Moretti, Shlomo and Sakshaug, 2019). Given the differing directions of scores across these three dimensions their labelling varies across Figure 2-4: higher scores on the economic and moral dimensions reflect higher levels of concern with welfare spending on those grounds whilst higher scores on the social dimension reflects higher levels of support for welfare spending on that basis. Caterpillar plots of confidence intervals around these point estimates are shown in the Appendix (Figure 1A, 2A and $3 \mathrm{~A})$.

Looking across Figures 2-4 it can be seen that there is diversity both between but also to vary degrees within countries. Turning first to Figure 2 it can be seen that attitudes around the economic consequences of social welfare benefits in the UK and France are strongly towards their placing too great a strain on the economy. There is only slight sub-national variation in these countries with Scotland, Cornwall and regions across north-west France somewhat less strong in their level of economic concern. Although not quite as strong as in UK and France, relatively high levels of attitudinal concern around the cost of social benefits to the economy can also be seen across Poland, Czech Republic and Slovenia. This is particularly true of eastern Czech Republic and southern Poland and, interestingly, is in contrast to some regions of northern Poland which show only moderate attitudinal concerns about the economic costs of social benefits. Conversely, Germany, Switzerland, Sweden and Norway show relatively low levels of attitudinal concern with the economic costs of social benefits, though with some regional variation visible around these always relatively low levels of economic concern.

As previously noted, economic attitudes towards social benefits correlate highly with moral attitudes towards welfare benefits, with the Spearman's rank correlation between the two large and positive $(+0.85)$. A similar regional pattern of moral welfare attitudes therefore 
emerges as shown in Figure 3. Despite many similarities to the sub-national spatial patterning of economic welfare attitudes, however, some important differences to those economic concerns can be seen. Whilst some variation exists across Polish regions in the degree of concern over the economic costs of social benefits, Polish regions are united in their high degree of concern around the moral costs of such benefits. Whilst southern regions of Norway and Sweden are relatively similar in their low levels of concerns around economic costs of social benefits, southern regions of Sweden show greater concern for the moral costs of benefits compared with southern regions of Norway. German regions show somewhat higher levels of attitudinal concern around the moral costs of social benefits compared to their economic costs, with only slight variation regionally in these views.

The regional patterning of attitudes around the social costs of benefits shows a very different picture as presented in Figure 4. Citizens across all Scandinavian regions stand out in their strong belief in the positive social consequences of welfare benefits. In contrast, regions across the UK, Northern Ireland (though, interestingly, not Republic of Ireland), Poland (especially central Poland), Estonia and Czech Republic show only weak attitudinal support for the idea of social benefits as alleviators of poverty and inequality. The case of Estonia is particularly interesting in that although there is little concern around the economic or moral costs of benefits Estonia also shows little support for positive social consequences of benefits either, in contrast to the patterns seen across the more social democratic Scandinavian regions. Regions of Belgium and Netherlands also stand out. Whilst these regions align closely with those of Germany in their welfare attitudes around the economic and moral consequences of benefits, in terms of their social consequences regions across Belgium and Netherlands show a markedly more positive view of the positive social consequences of benefits than do German regions. Whilst a continental European welfare regime is often espoused therefore (Esping-Andersen, 1990; Arts and Gelisson, 2010) these analyses highlight that the picture is somewhat more complex in terms of welfare attitudes when assessed in a more spatially nuanced multi-dimensional perspective. 


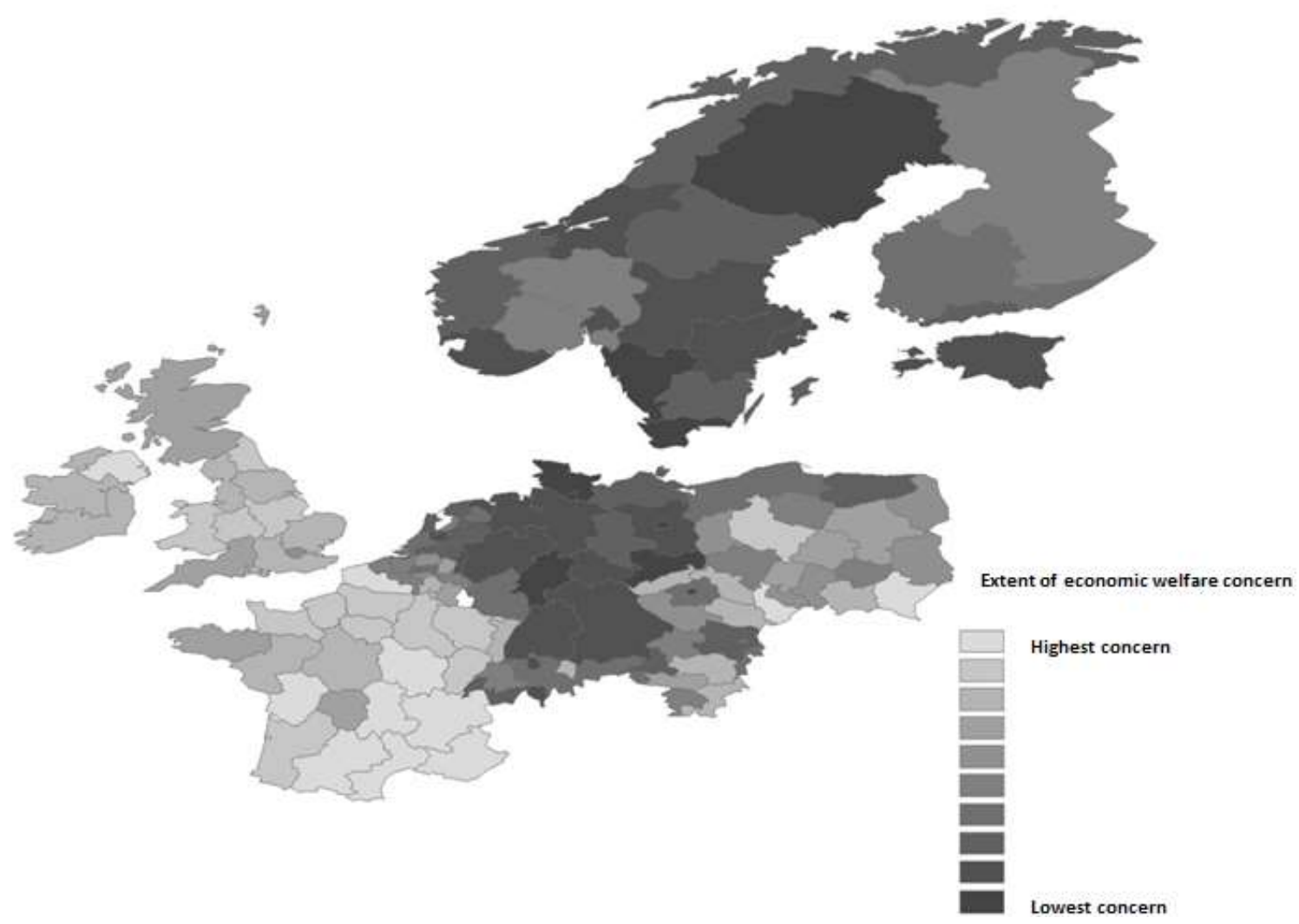

Figure 2 European regional attitudes of the economic consequences of welfare benefits

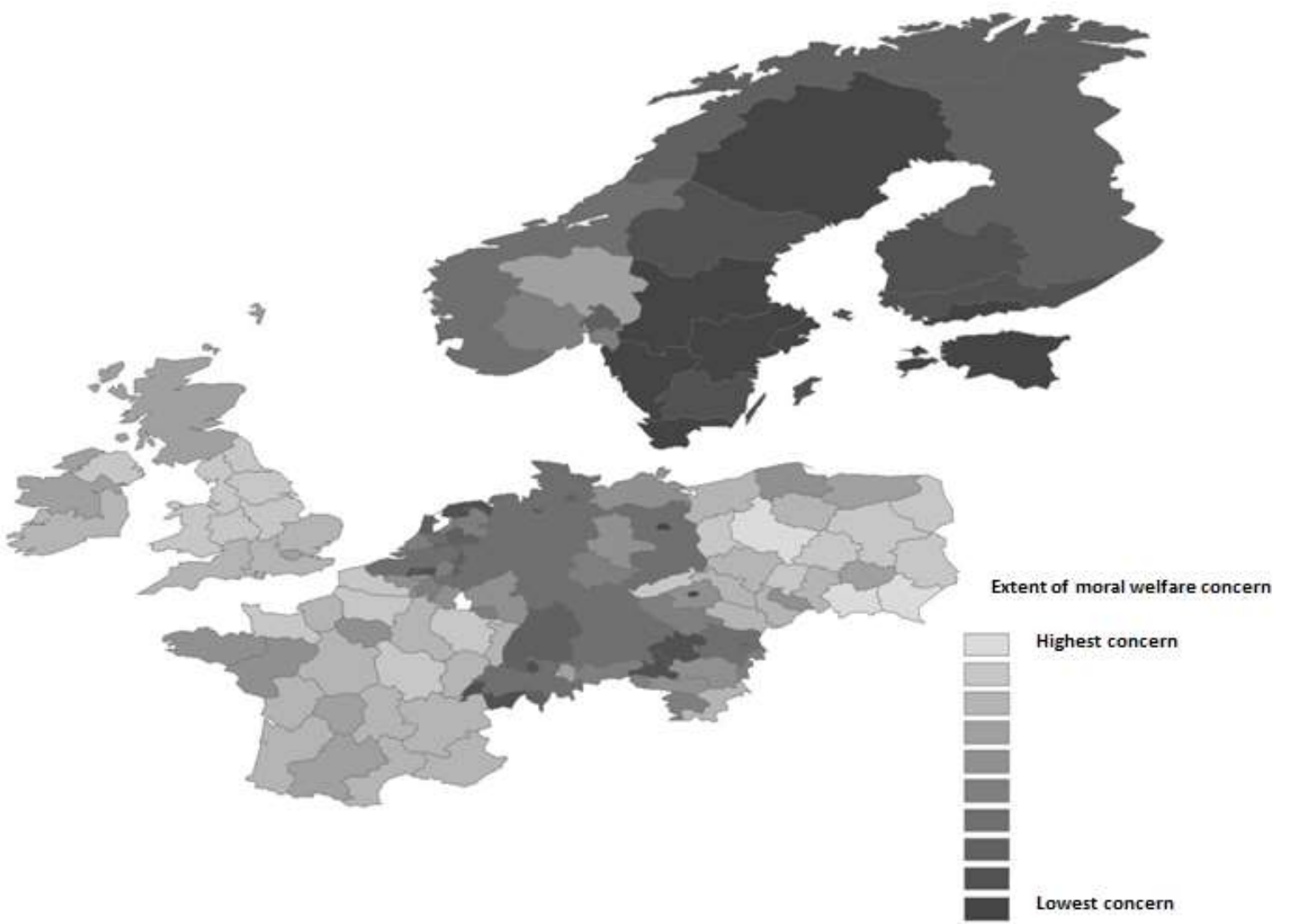

Figure 3 European regional attitudes of the moral consequences of welfare benefits 


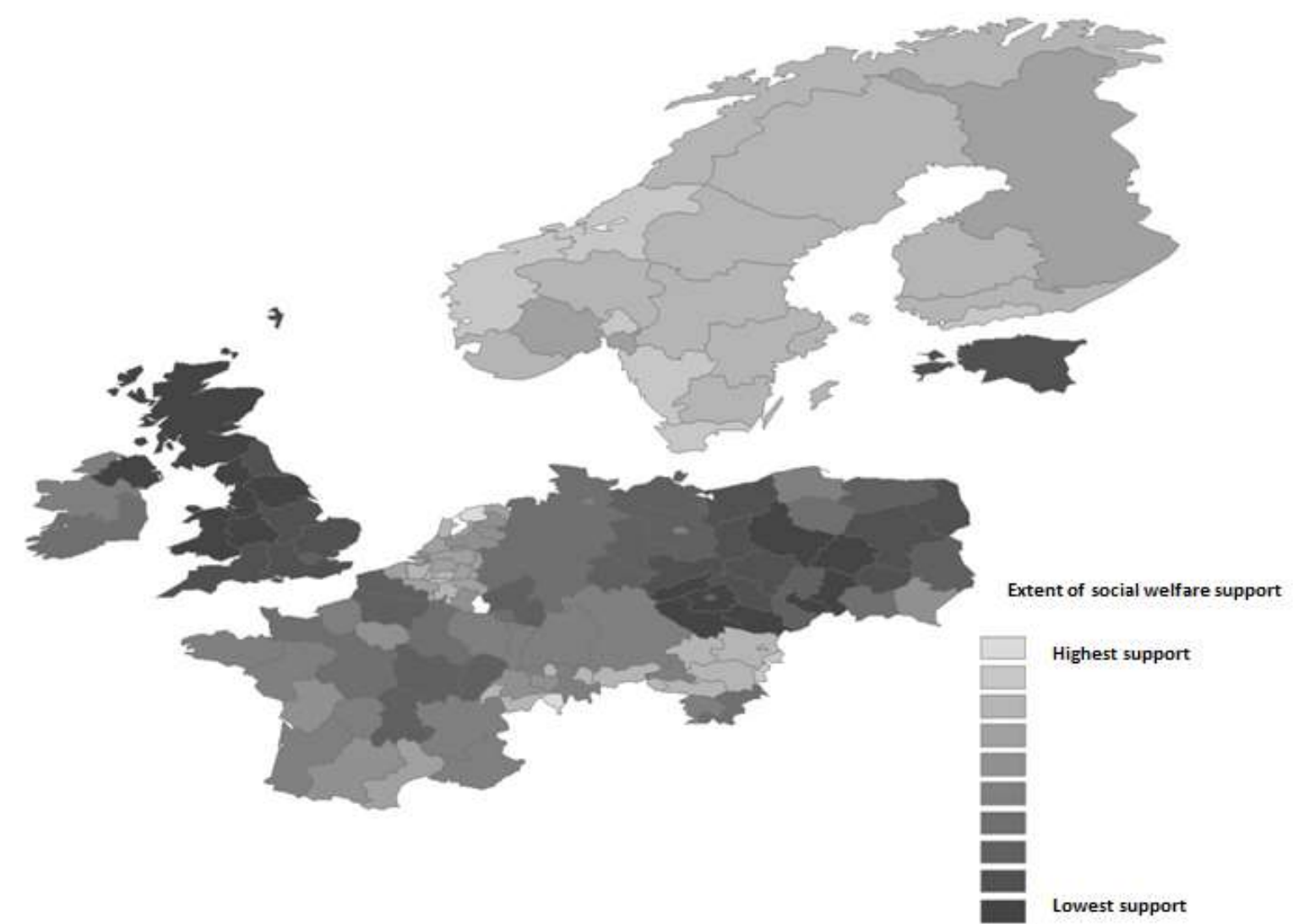

Figure 4 European regional attitudes of the social consequences of welfare benefits

\section{Regional worlds of welfare attitudes across Europe?}

The regional and multi-dimensional analyses presented above offer new layers of understanding to the comparative nature and spatial patterning of regional welfare attitudes across Europe. In that richness comes complexity however such that additional efforts to synthesise emerging patterns take on their own analytical value. As such, the analyses below make use of cluster analysis techniques on each region's scores across the economic, social and moral dimensions to explore whether distinct 'families' of regional welfare attitudes exist across Europe and, if so, the extent to which they map onto or possibly transcend the national boundaries that dominate comparative research. In doing so these classificatory analyses both provide helpful synthesis of the rich sub-national patterns seen as well as enabling our comparative thinking around regional welfare attitudes to transcend the typical spatial assumptions of traditional nation-based comparative European analysis.

A series of exploratory k-means cluster analyses were performed and the resulting scree plot of the within groups sum of squared errors (SSE) highlights that the optimal number of clusters lies between 4 and 6 inclusive. Further detailed analyses suggest that 5 clusters are optimal. Figure 5 summarises visually the cluster centres of those five cluster groups across their constituent economic, social and moral dimensions and labels each regional family according to those attitudinal characteristics. 


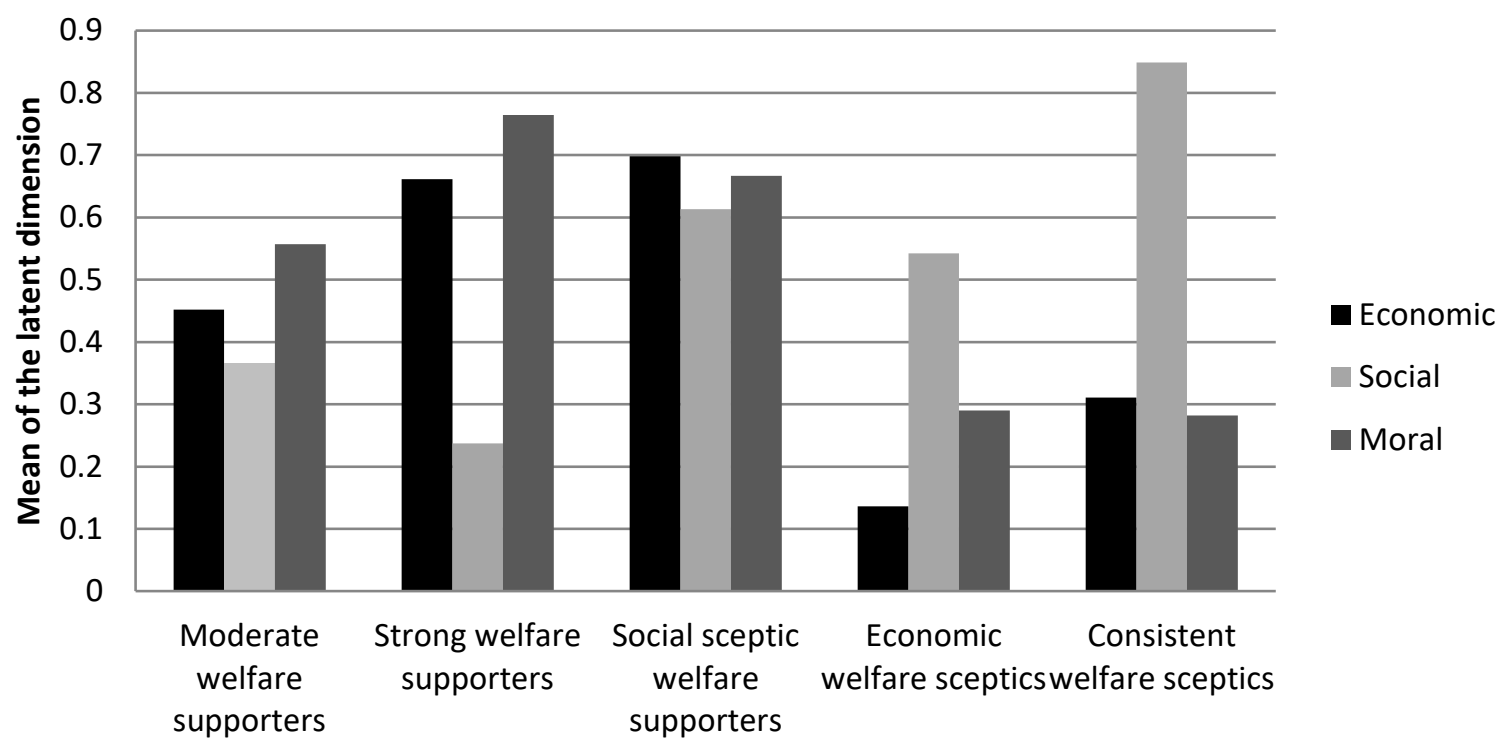

Figure 5 Europe's five families of regional welfare attitudes

Naturally, of key interest is to understand the regional membership of each of these distinct families of welfare attitudes and in doing so to compare and contrast them with existing European welfare typologies (Esping-Andersen, 1990; Arts and Gelisson, 2010). Figure 6 summarises these spatial patterns both within and between countries.

In contrast to the continental European welfare family identified within the welfare typologies literature these analyses suggest a more heterogeneous picture. Within that standard continental European group Germany stands largely alone in being differentiated by its larger extent of social concern for welfare compared to its more general moral and economic positivity towards welfare. In contrast, France, along with the Republic of Ireland, is differentiated by its larger extent of economic concern for welfare compared to its more general moral and social positivity towards welfare. Also notable within France are differences in regional attitudes in the Brittany and Limousin regions, with citizens there being less concerned than mainstream France with economic welfare consequences and hence being described instead as moderate welfare supporters. Whilst the Nordic countries stand out as moderate or (mainly) strong welfare supporters in line with welfare typologies scholarship, it is notable that regions across Belgium, Netherlands, Switzerland, , and much of Austria are identified similarly rather than as within the same welfare attitudes family as other continental European regions.

Interestingly, some regions of southern Poland join France in this welfare attitudes family. Interesting, there are similarities between these areas and the Pomorskie region in north of Poland which follows a different pattern from the remainder of the country.

Interesting results are found in the regions located as within family of consistent welfare sceptics. Of note firstly is the similarly between the sceptical attitudes of Great Britain and the remainder of the United Kingdom in Northern Ireland, despite the physical separation and complex political history of those nations. Of interest too are the attitudinal findings of regions across the Baltic nations. In particular, Czech Republic and core regions of Poland join the United Kingdom in this consistently sceptical welfare attitudes family of regions that welfare typologies scholarship would frequently - and partly misleading in this context describe as an Anglo-Saxon cluster. In contrast, border regions of Poland to the south and 
north are interesting differentiated into less sceptical attitudinal welfare families, identified with moderate or strong welfare supporting regions in northern regions bordering Lithuania and out into the Baltic Sea towards Scandinavia and with economically sceptical welfare regions along the southern border with Slovakia and the Czech Republic.

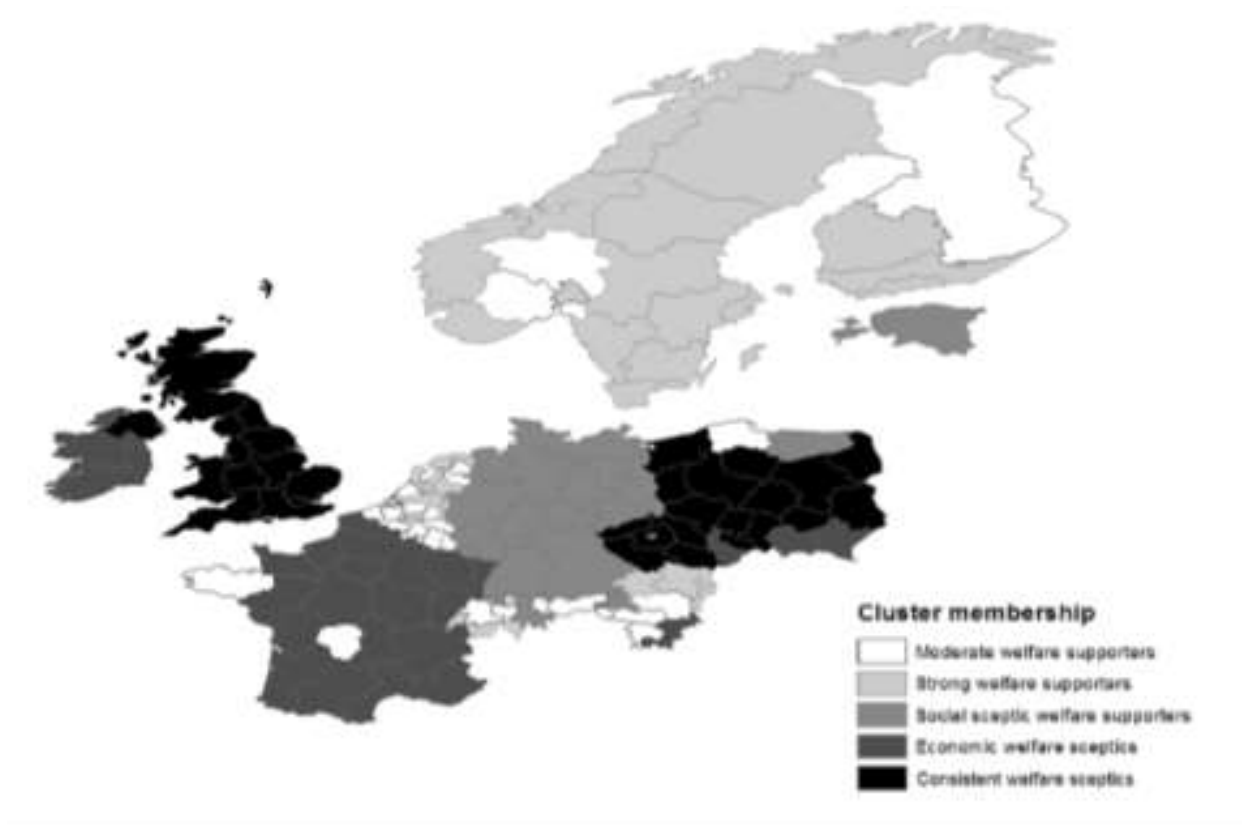

Figure 6 Europe's five families of regional welfare attitudes

\section{Conclusion}

This paper has sought to advance the more nuanced spatial understanding of multidimensional welfare attitudes across European regions through the utilisation of composite small area estimation techniques in order to progress scholarly and policy understanding beyond the high-level national insights that dominate currently. Such original sub-national understandings of welfare attitudes are important to reveal given the key political and policy roles and responsibilities of local governments across western democracies.

The economic and moral dimensions are highly correlated and regional attitudes around welfare tend therefore to run in parallel with each other across them. The highest levels of region concern at the economic and moral consequences of social benefits exist across the UK and Poland whilst the most positive views are held across Scandinavia and, in respect of economic consequences, parts of Germany and France tend to occupy the centre ground. In respect of regional attitudes towards the social consequences of welfare the UK and much of Eastern Europe show the lowest levels of support for welfare on social grounds whilst the highest levels of support on social grounds come again from Scandinavia but also from parts of Belgium and the Netherlands.

The bringing together of these findings into the original empirical identification of five European 'families' of regional welfare attitudes helpfully syntheses the key messages. These welfare attitudes families draw out a range of attitudinal positions from consistently strong welfare supporters (regions across Scandinavia, Belgium, Netherlands, Switzerland, Hungary, Slovakia and much of Austria) to consistent welfare sceptics (the UK and eastern 
European regions), with other regional groupings differentiated by particular positions on certain economic (regions across France, Republic of Ireland and southern Poland) or social (German regions particularly) dimensions. Whilst based broadly around national boundaries and existing national-level welfare typologies, the shift to a richer sub-national perspective enables the identification of notable within-country and cross-national regional clusters of welfare attitudes. This questions the continued reliance on the nation state as the default spatial unit with which to examine and typologize welfare attitudes and wider social policy phenomenon.

Like van Oorschott et al. (2012), our analyses also find that economic attitudes towards social benefits tend to run in parallel with moral attitudes towards social benefits but in the opposing direction to social attitudes. The implication, as van Oorschott et al. (2012) notes, is that welfare attitudes are not a unidimensional and zero-sum game as many individuals hold both positive and negative attitudes across the three latent economic, moral and social dimensions of welfare attitudes. At a time of varying degrees of on-going austerity and downwards pressures on welfare across European nations these are important considerations as increases in welfare spending should be expected to generate both positive and negative attitudinal responses. Thus, assessment of net attitudinal change and awareness of which attitudinal aspects of welfare systems become the focus of media and public attention become key (Baumberg Geiger and Meueleman, 2016). Our analyses push these insights further through the acknowledgement that these linkages do not occur in a socio-spatial vacuum but, rather, always take place within spatial contexts and communities. Greater awareness of that sub-national spatial variation in welfare attitudes and their connections to wider political and policy contexts is of significant importance to our on-going understanding in this key area of comparative social policy scholarship as we seek new ways to build social prosperity, inclusion and cohesion across European communities. 


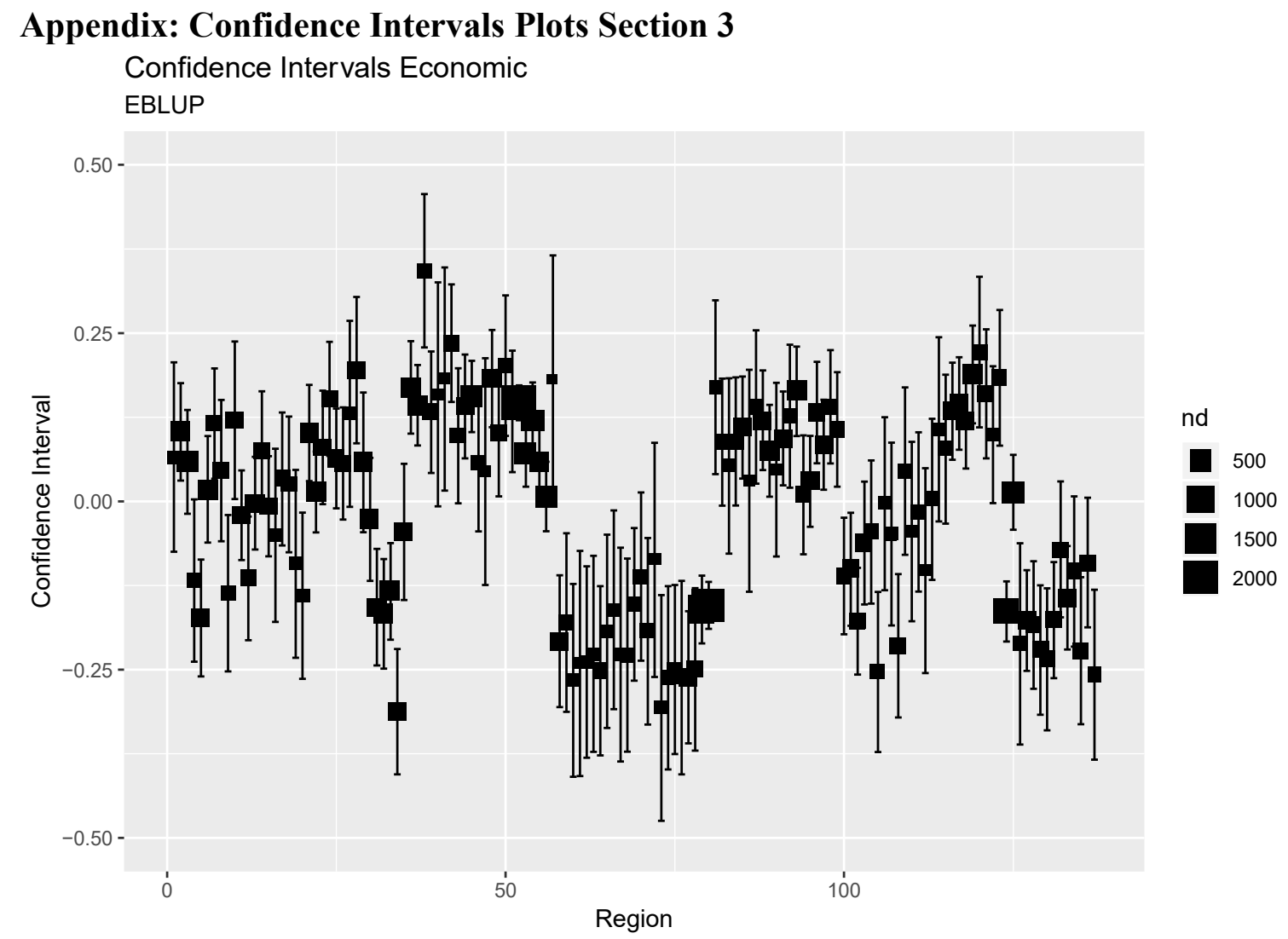

Figure A1 Confidence intervals economic factor EBLUP $\left(n_{d}\right)$ denotes the sample size in the region.

Confidence Intervals Moral

EBLUP

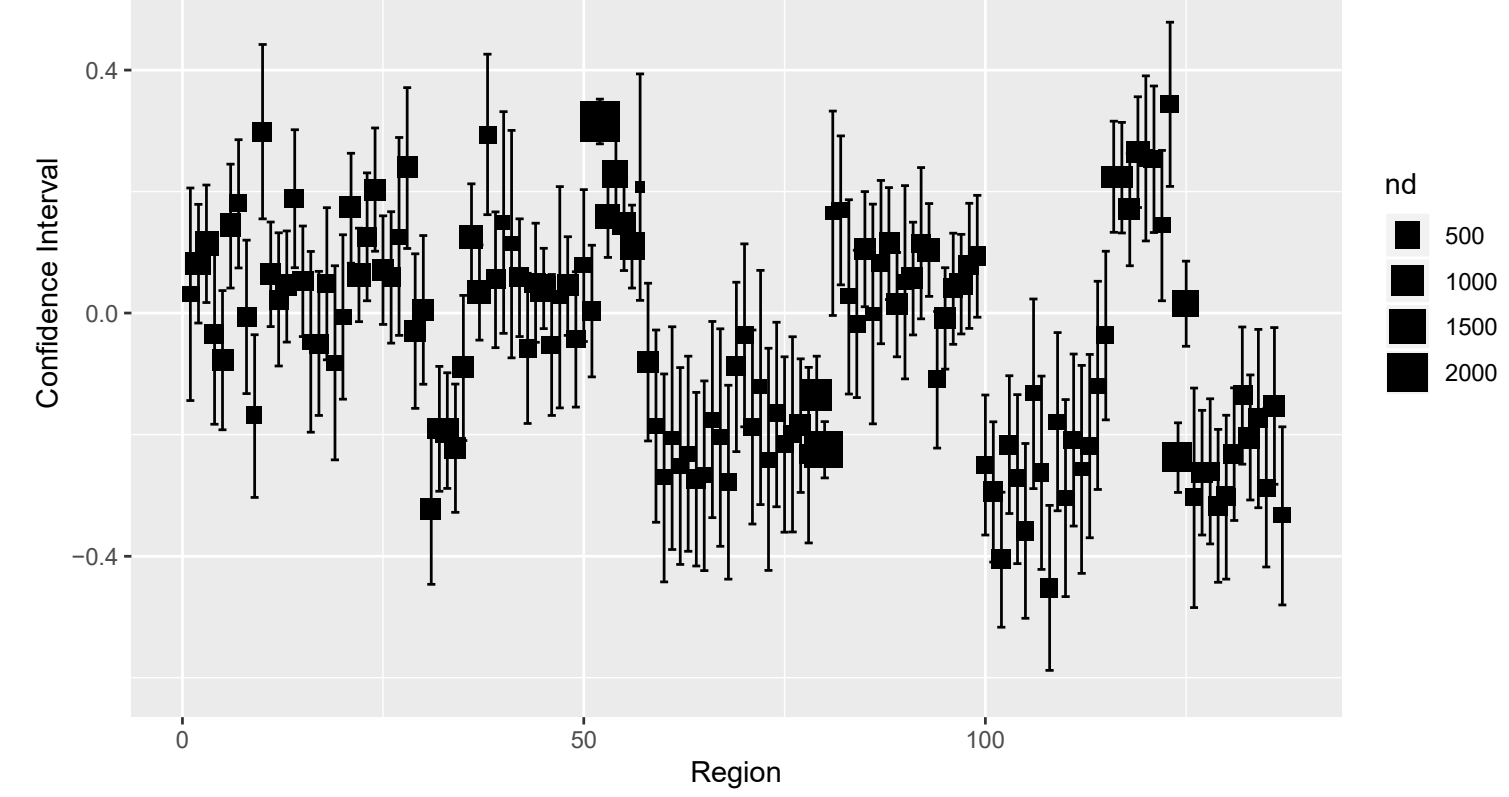

Figure A2 Confidence intervals moralc factor $\operatorname{EBLUP}\left(n_{d}\right)$ denotes the sample size in the region. 
Confidence Intervals Social

EBLUP

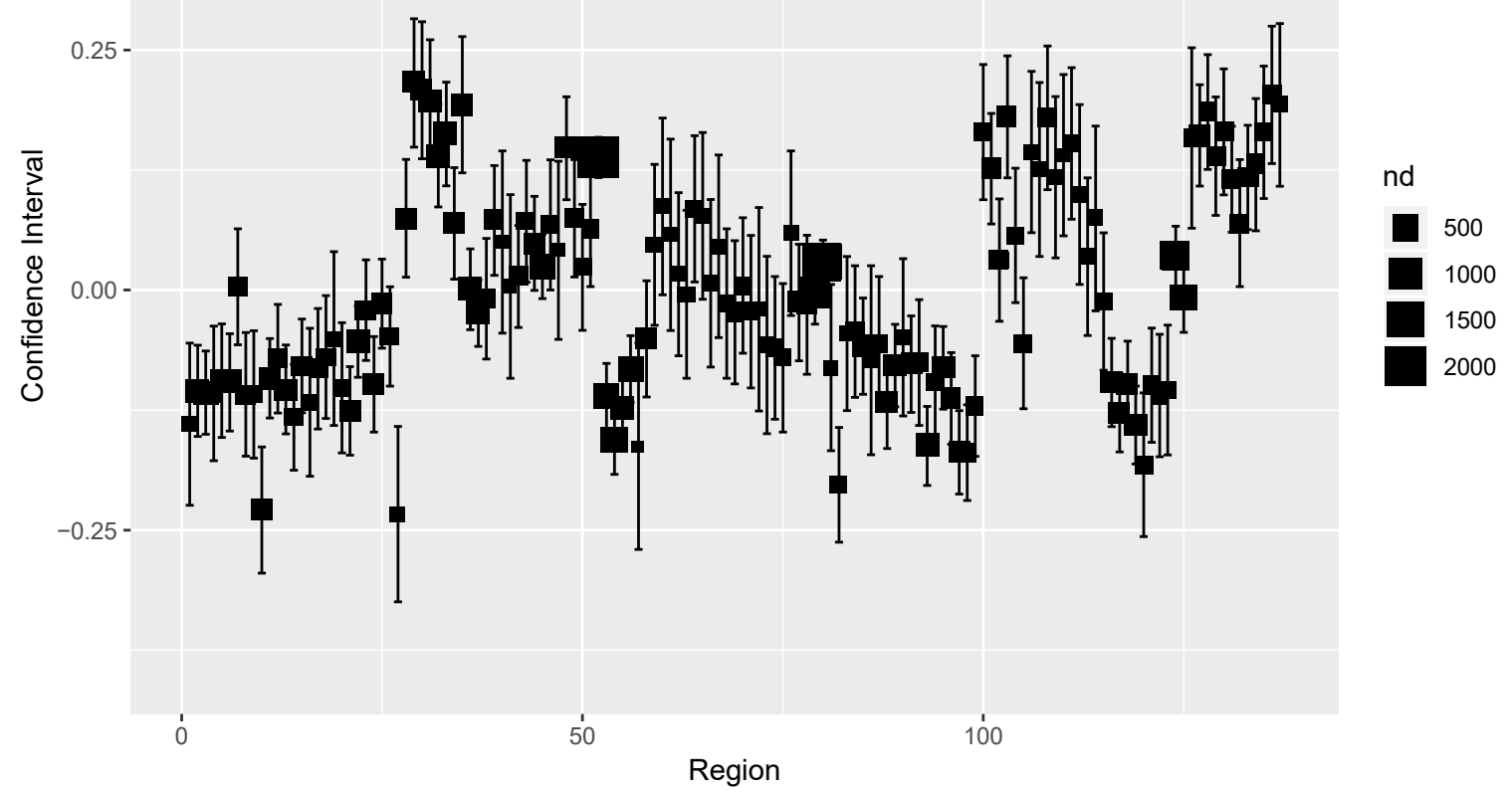

Figure A3 Confidence intervals social factor EBLUP $\left(n_{d}\right)$ denotes the sample size in the region. 


\section{References}

Almond, G. A. and Verba, S. 1963 The Civic Culture. Princeton, N.J.: Princeton University Press.

Arts, W and Gelisson, J. 2010. Models of the welfare state in Castles, F., Leibried, S., Lewis, J., Obinger, H. and Pierson, C. (eds) The Oxford Handbook of the Welfare State. Oxford: Oxford University Press.

Bartholomew, D. J., Steele, F., Moustaki, I. and Galbraith, J. I. (2008) Analysis of Multivariate Social Science Data. CRC.

Baumberg, B. 2014. Fit-for-Work - or Work Fit for Disabled People? 1 The Role of Changing Job Demands and Control in Incapacity Claims. Journal of Social Policy, 43(2), 289-310.

Baumberg Geiger, B. and Meueleman, B (2016) Beyond 'mythbusting': how to respond to myths and perceived undeservingness in the British benefits system, Journal of Poverty and Social Justice, 24(3), pp291-306

Baumberg Geiger, B. 2017. Sharp softening of attitudes to benefit claimants, reveals new data. Retrieved from https://inequalitiesblog.wordpress.com/2017/06/28/sharp-softeningof-attitudes-to-benefit-claimants-reveals-new-data/ (retrieved on $14^{\text {th }}$ June 2018).

Beresford, P. 2013. Why welfare literacy is vital. The Guardian, 30/1/2013.

Blekesaune, M., and Quadagno, J. (2003) Public attitudes toward welfare state policies: A comparative analysis of 24 nations. European Sociological Review, 19, 415-27.

Breznau, N (2017) Positive returns and equilibrium: Simulataneous feedback between public opinion and social policy, The Policy Studies Journal, 45(4), pp583-612

Brown, G., Chambers, R., Heady, P. and Heasman, D. 2001. Evaluation of small area estimation methods an application to the unemployment estimates from the UK LFS. Statistics Canada Symposium Ottawa, October 2001.

Buil-Gil, D., Moretti, A., Shlomo, N. and Medina, J. 2019. Worry about crime in Europe. A model-based small area estimation from the European Social Survey. European Journal of Criminology.

Buil-Gil, D., Medina, J., and Shlomo, N. 2019. The geographies of perceived neighbourhood disorder. A small area estimation approach. Applied Geography, 109.

DiStefano, C., Zhu, M. and Mindrila, D. 2009. Understanding and using factor scores: considerations for the applied researcher. Practical assessment, Research and Evaluation, 14(20).

Esping-Andersen, G. 1990. Three worlds of welfare capitalism. Princeton: Princeton University Press.

European Social Survey. 2018. ESS8 - 2016 Documentation Report - The ESS Data Archive Edition 2.1. Retried from https://www.europeansocialsurvey.org/docs/round8/survey/ESS8 data documentation $\mathrm{r}$ eport e02 1.pdf (14 May 2019).

Eurostat (2019) Population on $1^{\text {st }}$ January by NUTS2 region. [accessed $1^{\text {st }}$ June 2019] https://ec.europa.eu/eurostat/web/products-datasets/product?code=tgs00096

Fay, R.E. and Herriot, R.A. 1979. Estimates of income for small places: an application of James-Stein procedures to census data. Journal of the American Statistical Association, 74, 269-277.

Ghosh, M. and Rao, J. 1994. Small area estimation: an appraisal, Statisical Science, 9(1), 5576.

González-Manteiga, W., Lombardía, M.J., Molina, I., Morales, D. and Santamaría, L. 2008. Bootstrap mean squared error of a small-area EBLUP, Journal of Statistical Computation and Simulation, 78, 443-462. 
Gough, I. 2001. Normative and Consequentialist Arguments for the Welfare State', in A. Ben-Arieh and J. Gal (eds) Into the Promised Land: Issues Facing the Welfare State. Westport, CT: Praeger.

Hansen, T. and Klausen, J. E. 2010. Between the Welfare State and Local Government Autonomy. Local Government Studies, 28(4), 47-66.

Hershberger, S. L. 2005. Factor scores. In B. S. Everitt and D. C. Howell (Eds.) Encyclopedia of Statistics in Behavioral Science. (636-644). New York: John Wiley.

Horvitz D.G. and Thompson, D.J. 1952. A Generalization of Sampling without Replacement from Finite Universe. Journal of the American Statistical Association, 47, 663-685.

Hu, L., and Bentler, P.M. 1999. Cutoff criteria for fit indexes in covariance structure analysis: Conventional criteria versus new alternatives. Structural Equation Modeling, 6(1): 1-55.

Jakobsen, $\mathrm{T}$ (2011) 'Welfare attitudes and social expenditure: do regimes shape public opinion?', Social Indicators Research, 101, pp323-340

Laenen, T. 2018. Do institutions matter? The interplay between income benefit design, popular perceptions, and the social legitimacy of targeted welfare, Journal of European Social Policy, 28(1), 4-17.

Levy P.S. 1979 Small area estimation-Synthetic and other procedures, 1968-1978. In: Steinberg J (ed) Synthetic estimates for small areas: Statistical workshop papers and discussion. Rockville, National Institute on Drug Abuse, 4-19.

Marshall, A. 2010. Small area estimation using ESDS government surveys - An introductory guide Economic and Social Data Service.

Moretti, A., Shlomo, N. and Sakshaug, J. (2019) Small Area Estimation of Latent Economic Wellbeing. Sociological Methods \& Research

Moretti, A and Whitworth, A (2019) Evaluations of small area composite estimators based on the iterative proportional fitting algorithm, Communications in Statistics - Simulation and Computation

OECD-JRC. 2008. Handbook on constructing composite indicators: methodology and user guide. OECD Statistics report. (Available from http://www.oecd.org/std/42495745.pdf, retrieved on $19^{\text {th }}$ December 2018).

Pratesi, M. (ed.) 2016. Analysis of Poverty Data by Small Area Estimation. Wiley.

Rahman, A. 2008. A review of small area estimation problems and methodological developments. University of Canberra: NATSEM Discussion Paper Issue 66.

Rao, J.N.K. and Molina, I. 2015. Small Area Estimation. Wiley.

Roller, E. 1995. The welfare state: The equality dimension. In: Borre, O. and Scarbrough, E. (ed.), The Scope of Government, Oxford: Oxford University Press, 165-197.

Roosma, F., Gelissen, J. and Van Oorschot, W. 2013. The multidimensionality of welfare state attitudes: A European cross-national study. Social Indicators Research, 113(1), 235 255.

Roosma, F., van Oorschot, W. And Gelissen, J. 2014. The preferred role and perfceived performance of the welfare state: European welfare attitudes from a multidimensional perspective, Social Science Research, 44, 200-210

Scarborough P., Allender S., Rayner M., Goldacre M. 2009. Validation of model-based estimates (synthetic estimates) of the prevalence of risk factors for coronary heart disease for wards in England. Health Place, 15(2), 596-605.

Slater, T. 2012. The Myth of "Broken Britain": Welfare Reform and the Production of Ignorance. Antipode, 46(4), 948-969.

Svallfors, S. 2004. Class, Attitudes and the Welfare State: Sweden in Comparative Perspective. Social Policy \& Administration, 38(2), 119-138

Svallfors, S. 2012. (ed.) Contested welfare states: welfare attitudes in Europe and beyond. Stanford, CA: Stanford University Press 
Svallfors, Sand Taylor-Gooby, P. 2012. The end of the welfare state? Responses to state retrenchment. London: Routledge.Taylor-Gooby, P. 2011. 'Security, equality and opportunity: attitudes and the sustainability of social protection', Journal of European Social Policy, 21(2), pp150-163

Taylor-Gooby, P and Leruth, B. 2018. (eds.) Attitudes, aspirations and welfare: Social policy directions in uncertain times. Oxford: Palgrave Macmillan

Toikko, T. and Rantanen, T (2017) How does the welfare state model influence social political attitudes? An analysis of citizens' concrete and abstract attitudes towards poverty, Journal of International and Comparative Social Policy, 33(3), pp201-224Van Oorschot, W. 2010. Public Perceptions of the Economic, Moral, Social and Migration Consequences of the Welfare State: An Empirical Analysis of Welfare State Legitimacy, Journal of European Social Policy 20(1): 19-31.

Van Oorschot, W., Reeskens, T. and Meuleman, B. 2012. Popular perceptions of welfare state consequences: A multilevel, cross-national analysis of 25 European countries. Journal of European Social Policy, 22(2), 181-197.

Whitworth, A. 2013. (ed.) Evaluations and improvements in small area estimation methodologies. National Centre for Research Methods Methodological Review paper.

Whitworth, A and Carter, E. 2015. Understanding Wales at the small area level: maximizing the performance of small area estimation. Cardiff: Welsh Government.

Wiggan, J. 2012. Telling stories of 21st century welfare: The UK Coalition government and the neo-liberal discourse of worklessness and dependency. Critical Social Policy, 32(3). 